FINAL REPORT

U. S. Department of Energy

\title{
INVESTIGATIONS OF TECHNIQUES TO IMPROVE CONTINUOUS AIR MONITORS UNDER CONDITIONS OF HIGH DUST LOADING IN ENVIRONMENTAL SETTINGS
}

\author{
Principal Investigator: Suilou Huang \\ Institution: New Mexico Institute of Mining and Technology \\ Collaborators: Stephen D. Schery ${ }^{*}$, John C. Rodgers ${ }^{*}$ \\ Collaborators' Institutions: *New Mexico Institute of Mining and Technology \\ ** Los Alamos National Laboratory \\ Project number: 60163 \\ Grant Number: DE-FG07-97ER62519 \\ Grant Project Officers: Roland Hirsch, Mark Gilbertson
}

Project Duration: 9/15/1997 through 3/31/2002 


\section{Table of Contents}

1. Cover Page $\quad$..................................................................................... 1

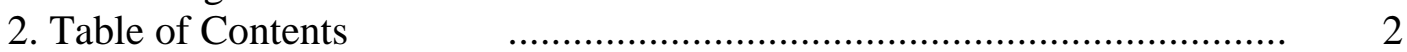

3. Executive Summary $\quad$............................................................... 3

4. Research Objectives $\quad$.............................................................. 5

5. Method and Results $\quad$..................................................................... 7

5.1 Pulse Ionization Chamber $\quad$........................................................ 7

5.2 New Method for Generating Radioactive Aerosols ...................... 9 for Testing ECAMs and the Alpha Particle Energy Resolution of Filters

5.3 The Effect of Dust Loading on the Alpha-Particle $\quad$...................... $\quad 10$ Energy Resolution of Filters

5.4 Test of a Prototype Virtual Impactor as the ECAM ..................... 13 Preseparator

6. Relevance, Impact, and Technology Transfer $\quad$.............................. 15

7. Project Productivity $\quad$............................................................................. 17

8. Personnel Associated with the Project $\quad$............................................ 18

9. Publications $\quad$............................................................................... 19

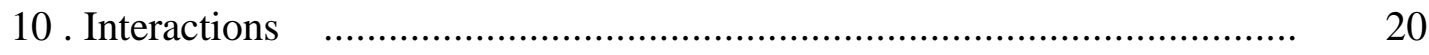

10.1 Presentations $\quad$.................................................................... 20

10.2 Consultations $\quad$................................................................... 20

11. Transitions $\quad$.......................................................................... 21

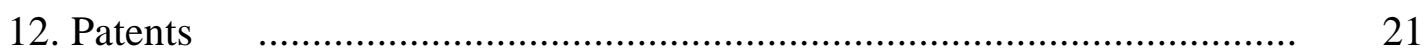

13. Future Work ............................................................................. 21

14. Literature Cited $\quad$......................................................................... 22

15. Feedback $\quad$.............................................................................. 23

16. Appendices $\quad$.......................................................................... 25

Abstracts of M. S. Thesis and Two Health Physics Papers 


\section{Executive Summary}

A number of Department of Energy facilities, such as the Los Alamos National Laboratory (LANL) and the Waste Isolation Pilot Plant (WIPP), use alpha-particle environmental continuous air monitors (ECAMs) to monitor air for unwanted releases of radioactive aerosols containing such materials as plutonium and uranium. High sensitivity, ease of operation, and lack of false alarms are all important for ECAMs. The object of the project was to conduct investigations to improve operation of ECAMs, particularly under conditions where a lot of nonradioactive dust may be deposited on the filters (conditions of high dust loading). The presence of such dust may increase the frequency with which filters must be changed and can lead to an increased incidence of false alarms due to deteriorated energy resolution and response specificity to the radionuclides of interest.

A major finding of the investigation, not previously documented, was that under many conditions thick layers of underlying nonradioactive dust do not decrease energy resolution and specificity for target radionuclides if the radioactive aerosol arrives as a sudden thin burst deposit, as commonly occurs in the early-warning alarm mode. As a result, operators of ECAMs may not need to change filters as often as previously thought and have data upon which to base more reliable operating procedures.

A second, serendipitous discovery of the project was development of a convenient technique to generate radioactive aerosols for testing of air monitoring equipment such as ECAMs. This technique involves using an electric field to deposit radioactive radon decay products on the surface of relative nontoxic aerosol powdered substrates such as gold, iron, and silicon particles. This technique can be done with simple facilities and equipment. It produces radioactive aerosol particles with short half-lives that should be less hazardous than is potentially the case when actual plutonium and uranium aerosol particles are used for testing. This technique can easily be adopted by a number of 
laboratories doing testing with radioactive aerosols and can help reduce the cost, and safety issues, associated with generation of radioactive aerosols.

A great deal of additional useful data was accumulated, such as information on optimum filters to use for ECAMs and alpha particle signals to be expected from different types of radioactive aerosol particles. Most of this information, as well as the above specific accomplishments, are discussed in detail in the three major publications resulting from this project. The first is the M. S. thesis of Raul Alcantara (Studies of the Effect of Dust Loading on the Alpha-Particle Energy Spectrum for Radioactive Aerosol Particles Deposited on Filters, New Mexico Institute of Mining and Technology, 2000). This thesis is available from New Mexico Institute of Mining and Technology. Two refereed papers have been accepted for publication in the scientific journal Health Physics and will soon be available in many scientific libraries: 1) Huang et al., Micrometer-Sized Short-Lived Radioactive Aerosol Particles for Convenient Use in Laboratory Measurements, and 2) Huang et al., Influence of Dust Loading on the AlphaParticle Energy Resolution of Continuous Air Monitors for Thin Deposits of Radioactive Aerosols. 


\section{Research Objectives}

The overall objective was to carry out studies to improve the detection of plutonium aerosols by environmental continuous air monitors (ECAMs), particularly in dusty environments. A number of alpha-particle ECAMs are used at DOE sites such as Los Alamos National Laboratory (LANL), NM and the Waste Isolation Pilot Plant (WIPP), NM to monitor for releases of plutonium aerosols. A particularly important function of ECAMs is to provide an early warning of unwanted releases. Although the use of ECAMs to detect plutonium aerosols has been common for a number of years, there are several areas of operation where improvements are needed to better optimize the monitoring process.

One recurring problem has been too high an incidence of false alarms created by interference from alpha-particle decay of naturally-occurring radon decay products whose concentration fluctuates with atmospheric conditions. A second issue is the need to have (within reasonable financial constraints) the sensitivity for detection of plutonium aerosols as high as possible due to the potential high inhalation health hazard from airborne plutonium and the desire for an early warning of an unwanted release. Dusty sampling conditions can exacerbate both of these issues. Large deposits of dust on filters reduce the resolution with which alpha particle decays from plutonium can be discriminated from alpha-particle decays from radon decay products. Large deposits of dust also clog filters, reduce airflow, and hence decrease the sensitivity for detecting airborne plutonium per unit volume of air.

Given the facilities and expertise available to the collaborators of this project, it was decided to focus investigations on the following questions as a strategy to advance the science of optimum detection of airborne plutonium. 1) Due to the larger air filters and airflow that pulse ionization chambers can handle, could they provide a superior detector over conventional solid state detectors for high detection sensitivity for airborne 
plutonium? 2) Which commercially available filters provide the best combination of good energy resolution and high airflow, particularly under dusty conditions that eventually clog the filters? 3) How does the problem of energy resolution and clogging under dusty conditions vary with type of nonradioactive dust, thickness of the dust layer, type of radioactive aerosols, and conditions of collection? For known dust and radioactive aerosol conditions, can this information be used to improve ECAM operation? 
5. Methods and Results

\subsection{Pulse Ionization Chamber}

A research prototype pulse ionization chamber was used to study whether large area pulse ionization chambers might provide an attractive alternative to conventional smallerarea silicon solid-state detectors for use in ECAMs. A larger area surface might enable use of much larger filters and higher volumetric flow rates for ECAMs, thus increasing their sensitivity. The ionization chamber used for this research was a modified version of the system described by Johansson et al. (1992). It had a physical surface diameter of $26 \mathrm{~cm}$, which is much larger than the approximately $4.5-\mathrm{cm}$ diameter silicon detectors used in many of LANL alpha-particle ECAMs. As tested by Johansson et al. (1992), the pulse ionization chamber used P-10 gas (90\% argon, 10\% methane) and had an underlying alpha particle resolution as small as $35 \mathrm{keV}$ for sources placed within the active volume of the chamber.

We modified the ionization chamber by placement of a thin film end window so that it could be continuously operated opposite a filter face without need for episodic mechanical entry through a sliding tray door. Such a configuration would be necessary for operation as part of an ECAM. Diffusion of P-10 gas through this end window requires a continuous supply of $\mathrm{P}-10$ gas. We typically required a flow of $\mathrm{P}-10$ gas of at least 0.05 liter per minute $(\mathrm{lpm})$ to replace gas losses and maintain alpha-particle gain and resolution. We experimented with different gases (including nitrogen, propane, and carbon dioxide), the use of oxygen getters, and different materials for the end window to see if this problem of diffusional losses of gas could be reduced. Thicker end windows would reduce diffusional losses but also decreased energy resolution due to energy absorption upon passage of alpha particles through the window. No ideal solution was found, with all combinations of window materials and gases requiring significant replacement of gas (many cubic centimeters) on, at least, a daily bases.

For most tests we settled on P-10 gas at a flow rate of about $0.051 \mathrm{pm}$ using a thin window material of $0.25 \mathrm{mg} \mathrm{cm}$ metalized polycarbonate (product B10, Alexander Vacuum Research, Greenfield, MA). This configuration was capable of providing an energy resolution better than $100 \mathrm{kev}$ full width at half maximum (FWHM) for $7.69 \mathrm{MeV}$ alpha particles under optimum measurement conditions (small pore filter, unattached radon decay products with negligible self absorption, no filter-window air gap). This configuration was used to study the energy resolution obtainable with different type of air filters that might be used with either an ionization chamber detector or a conventional solid-state silicon detector. Tests focused on comparing the energy resolution for 7.69 $\mathrm{MeV}$ alpha particles from decay of ${ }^{214} \mathrm{Po}$ after collection of attached radon decay products on the respective filters under similar collection and measurement conditions (see Table 1). These tests indicated that polytetrafluoroethylene membrane filters of various pore sizes generally provided the best combination of good energy resolution and low airflow resistance, supporting similar findings by Hoover and Newton (1993).

From the standpoint of energy resolution and stability of operation, the pulse ionization chamber was comparable to the conventional solid-state silicon detectors used with ECAMs. Furthermore, much larger filters could be used with our ionization 
Table 1. Alpha Particle Energy Resolution for Clean Filters

\begin{tabular}{|l|c|c|c|}
\hline Filter Type & $\begin{array}{c}\text { Face Velocity } \\
\left(\mathrm{cm} \mathrm{s}^{-1}\right)\end{array}$ & $\begin{array}{c}\text { FWHM } \\
(\mathrm{keV})\end{array}$ & $\begin{array}{c}\text { FWTM } \\
(\mathrm{keV})\end{array}$ \\
\hline $\begin{array}{l}5.0 \mu \mathrm{m} \text { cellulose membrane } \\
\text { Corning MFMB }\end{array}$ & 35 & $540 \pm 20$ & $2220 \pm 40$ \\
\hline $\begin{array}{l}3.0 \mu \mathrm{m} \text { cellulose membrane } \\
\text { Corning MFMB }\end{array}$ & 33 & $670 \pm 20$ & $2320 \pm 50$ \\
\hline $\begin{array}{l}1.2 \mu \mathrm{m} \text { cellulose membrane } \\
\text { Corning MFMB }\end{array}$ & 30 & $430 \pm 20$ & $1450 \pm 50$ \\
\hline $\begin{array}{l}1.0 \mu \mathrm{m} \text { polytetrafluoroethylene membrane } \\
\text { Corning FNMB }\end{array}$ & 26 & $95 \pm 15$ & $570 \pm 30$ \\
\hline $\begin{array}{l}1.2 \mu \mathrm{m} \text { cellulose membrane } \\
\text { Millipore RA }\end{array}$ & 26 & $340 \pm 20$ & $1160 \pm 40$ \\
\hline $\begin{array}{l}0.3 \mu \mathrm{m} \text { cellulose membrane } \\
\text { Millipore PH }\end{array}$ & 7 & $175 \pm 40$ & $760 \pm 40$ \\
\hline $\begin{array}{l}3.0 \mu \mathrm{m} \text { polytetrafluoroethylene membrane } \\
\text { Millipore FS }\end{array}$ & 35 & $170 \pm 30$ & $660 \pm 40$ \\
\hline $\begin{array}{l}3.0 \mu \mathrm{m} \text { cellulose membrane } \\
\text { Millipore SS }\end{array}$ & 30 & $150 \pm 20$ & $650 \pm 200$ \\
\hline $\begin{array}{l}\text { Glass fiber, Gelman A/E } \\
\text { Paper fiber, Gelman Whatman } 41\end{array}$ & 33 & $580 \pm 50$ & $2540 \pm 170$ \\
\hline $\begin{array}{l}\text { Notes: } 7.69 \text { MeV alpha particles from }{ }^{214} \text { Po; radon progeny collected outdoors under natural } \\
\text { conditions; } 400 \text { mesh pre-filter screen used to remove unattached progeny; estimated size of } \\
\text { progeny 0.2 to 0.6 } \mu \mathrm{m} \text { (except } 3.0 \mu \mathrm{m} \text { Millipore attached to dust);B(10) metalized film }(0.25 \mathrm{mg} \\
\text { cm }{ }^{-2} \text { polycarbonate) counter window; filter diameter } 102 \mathrm{~mm}\end{array}$ \\
\hline
\end{tabular}

chamber giving a much larger air sampling rate and hence sensitivity for a given filter face velocity. For example, a 142-mm-diameter filter could easily be counted with high detection efficiency on our ionization chamber compared with the 47-mm-diameter filter used with many LANL ECAMs. The result is a factor of $(142 / 47)^{2}=9.1$ greater volumetric flow rate for a given face velocity and pressure drop.

In spite of the above comments, except in special situations, the use of ionization chambers in ECAMs still does not seem practical and competitive for routine operations.There are several issues, but the main one is the need for standard ionization chambers to be provided with a continuous supply of gas such as P-10 gas. The inconvenience, expense, and lack of portability in continuously supplying gas (typically from heavy cylinders of compressed gas) seem to overwhelm the advantages of increased sensitivity for routine operations. We identified one possible strategy that might eliminate the need for a continuous external supply of gas: use air as the ionization gas in the chamber. Due to the formation of slow negative ions in the presence of oxygen, it is then not possible to operate the chamber in the usual fast (microsecond electron collection times) pulse mode. However, ECAMs typically involve low count rates for 
which the slow (millisecond ion collection times) pulse mode is adequate. With modern electronic components and digital signal processing techniques, it might be possible to design a preamp and signal processor capable of operating with sufficient energy resolution in a slow pulse mode. Although we spent a little time looking into such a design, we soon realized it would be a challenging research project beyond the scope, budget, and expertise of the present project.

\subsection{New Method for Generating Radioactive Aerosols for Testing ECAMs and the Alpha Particle Energy Resolution of Filters}

Although it was not a programmed part of our original research plan, in the course of starting the tests of the effect of dust loading of filters on their alpha-particle energy resolution we came up with a new, convenient method for generating radioactive aerosols for laboratory measurements. This technique was significant enough that we spend some extra time developing and refining it. This research has been reported in the paper by Huang et al. (2002).

Briefly, the problem we encountered, and had to overcome, was that standard methods for producing radioactive test aerosols, particularly in the micrometer-size range, often involve expensive, sophisticated facilities requiring fairly rigorous health and radiation safety procedures and controls. This is particularly true if tests involve aerosols of plutonium, which are very toxic. Most of our experimental work was done on the campus of NMIMT, which has limited radiation safety facilities. Furthermore, our project involved use of students (including summer workers) for which it is difficult to provide the rigorous radiation safety training and workplace control possible with professional employees at national laboratories. The solution we arrived at was to generate radioactive aerosols by depositing radon decay products on commercially available nonradioactive powdered substrates that were generally of low toxicity (gold particles, glass beads, etc.). The important radon decay products have short half-lives (less than one hour for ${ }^{222} \mathrm{Rn}$ decay products) making mute any long-term radioactive disposal problem. Furthermore, in the case of accidental inhalation (none actually occurred in our work), potential integrated radiation doses to the lung would be much below that normally received from the natural radon decay products pervasive in indoor and outdoor air.

Figure 1 summarizes this technique. Radon gas from a commercial generator (containing $289 \mathrm{kBq}$, or $7.8 \mu \mathrm{Ci}$, of ${ }^{226} \mathrm{Ra}$ ) is passed through an inverted cup. A nonradioactive powdered substrate, such as gold particles or glass beads, is spread over a metal planchet at the bottom of the cup. A downward directed electric field from electrodes within the cup deposits atoms of ${ }^{218} \mathrm{Po}$ from decay of ${ }^{222} \mathrm{Rn}$ onto the powdered substrate. Following exposure (usually 30 to 60 minutes), the powdered substrate is removed from the cup and aerosolized in a chamber by a technique such as pneumatic dispersion. We typically start with 5 to $20 \mathrm{mg}$ of powdered substrate and (for our particular radon source) achieve a resulting activity (reported in terms of ${ }^{214} \mathrm{Bi}$ ) of about $5-50 \mathrm{~Bq} \mathrm{mg}{ }^{-1}$. We have successfully used this technique to generate radioactive aerosol particles from substrates of gold, glass, iron, iron oxide, and silica over a size range of 0.3 to $30 \mu \mathrm{m}$. The high-density gold particles, in particular, were believed to provide a good 


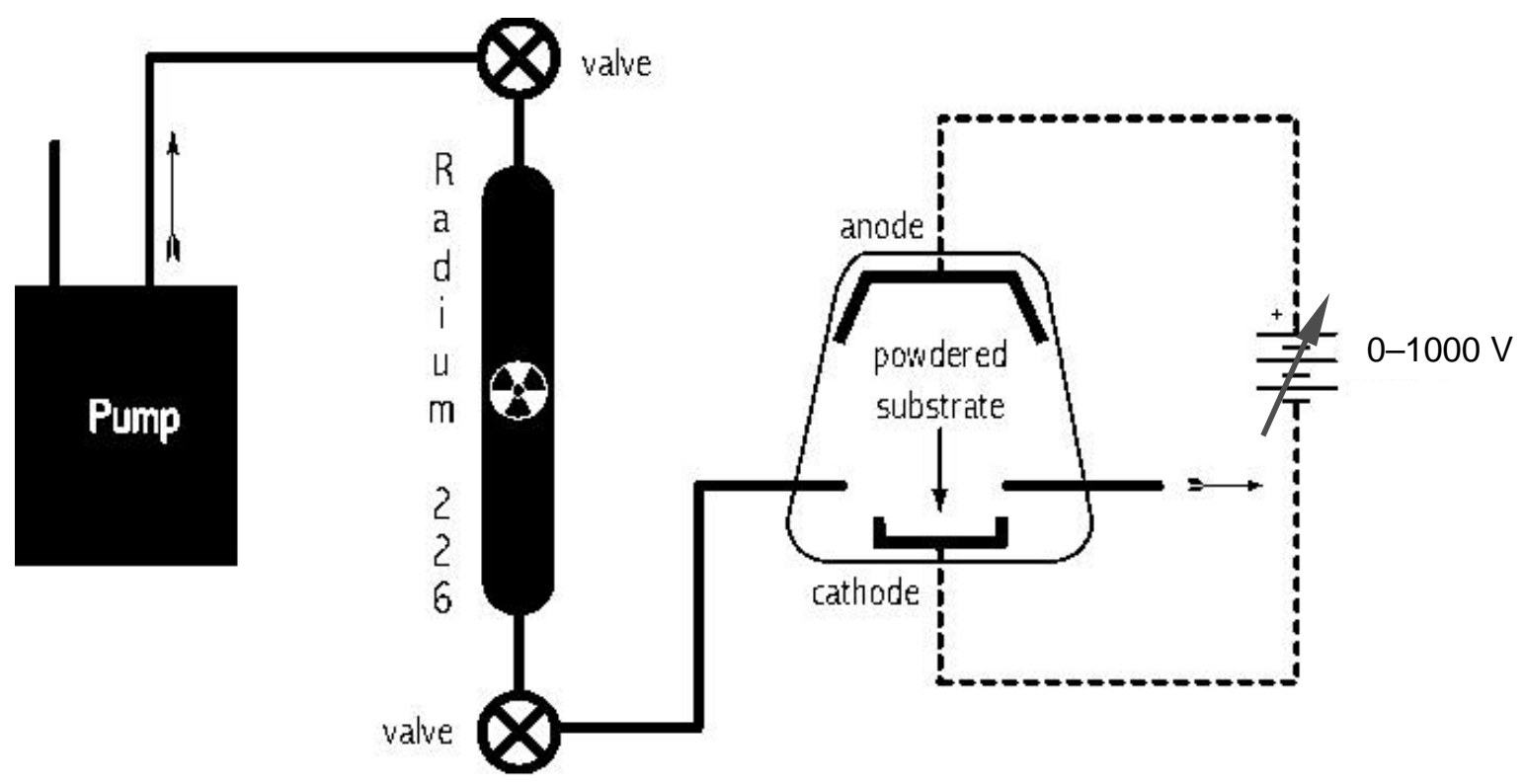

Figure 1. Experimental Arrangement for Generating Radioactive Aerosol Particles.

simulation of many of the plutonium aerosol particles an ECAM might be expected to detect. This technique results in a deposit of surface activity on aerosol particles that can result in slightly different alpha particle spectral characteristics than is the case with internally distributed activity. Further details of this technique can be found in Huang et al. (2002).

\subsection{The Effect of Dust Loading on the Alpha-Particle Energy Resolution of Filters}

Extensive study was done of the effect of loading of filters with nonradioactive dust on the alpha particle energy resolution of radioactive aerosols. This issue arises in connection with sampling sites such as at WIPP where ECAMs may be subject to more loading and/or clogging with dust than is common with some of the cleaner environments of indoor air. An important question is whether the presence of dust reduces alpha particle energy resolution thus requiring more frequent filter changes. More generally, we need to improve the scientific information about dust loading of filters so as to deal better with a range issues that are known or might arise in the future.

We made extensive studies of dust loading for different types of filters, for different types of nonradioactive dust, for different types of radioactive aerosols, and for different conditions of dust loading. We developed computer models for the alpha particle spectra to be expected with different types of radioactive aerosol particles. A report of this work is available in great detail in the M.S. thesis of Raul Alcantara (Alcantara, 2000) and a follow-up paper (Huang et al., 2002), so we will here mention only a few high points.

It was no surprise that when radioactive aerosol particles were deposited on filters at the same time as nonradioactive dust, and intermixed with it, the alpha particle energy 
resolution deteriorated as the thickness of this intermixed layer increased. We also obtained good data documenting the gradual deterioration of resolution as the size of radioactive aerosol particles increased (particularly for diameters greater than about $0.5 \mu \mathrm{m}$ ). These results follow from alpha particle energy absorption theory and have been noted by others (although our work comparing aerosol particles with surface distributed radioactivity to internally distributed radioactivity was new). However, to our surprise, we found that if a thin layer of radioactive aerosols arrived separately on top of an underlying layer of nonradioactive dust of varying thickness, typically there was no significant deterioration in the alpha particle resolution as observed by a detector placed opposite the face of the filter. This type of situation might be encountered by the common use of ECAMs as an "early warning" detector of unwanted pulsed releases of radioactive aerosols. To the extent our observations hold true in operational settings, other than varying resistance to airflow (easily monitored by the pressure drop), the presence of prior nonradioactive dust may have little effect on the alpha particle energy resolution and early-warning capability of an ECAM. The frequency with which filters must be changed may be less than previously thought.

Our studies involved the use of three different types of dust: that from Portland/Gypsum cement, that from powdered kaolinite/quartz clay, and that from salt aerosols generated by an atomizer. Figure 2 shows size (particle volume) distributions for the cement and clay dusts compared with data for outdoor air at WIPP. Although our laboratory dusts have a larger component in the micrometer size range, there is similarity in overall structure of the three size distributions. The atomizer generated salt distribution (not shown) is somewhat similar but with a smaller component in the micrometer size range. We feel that the cement and clay dusts should be fairly typical of
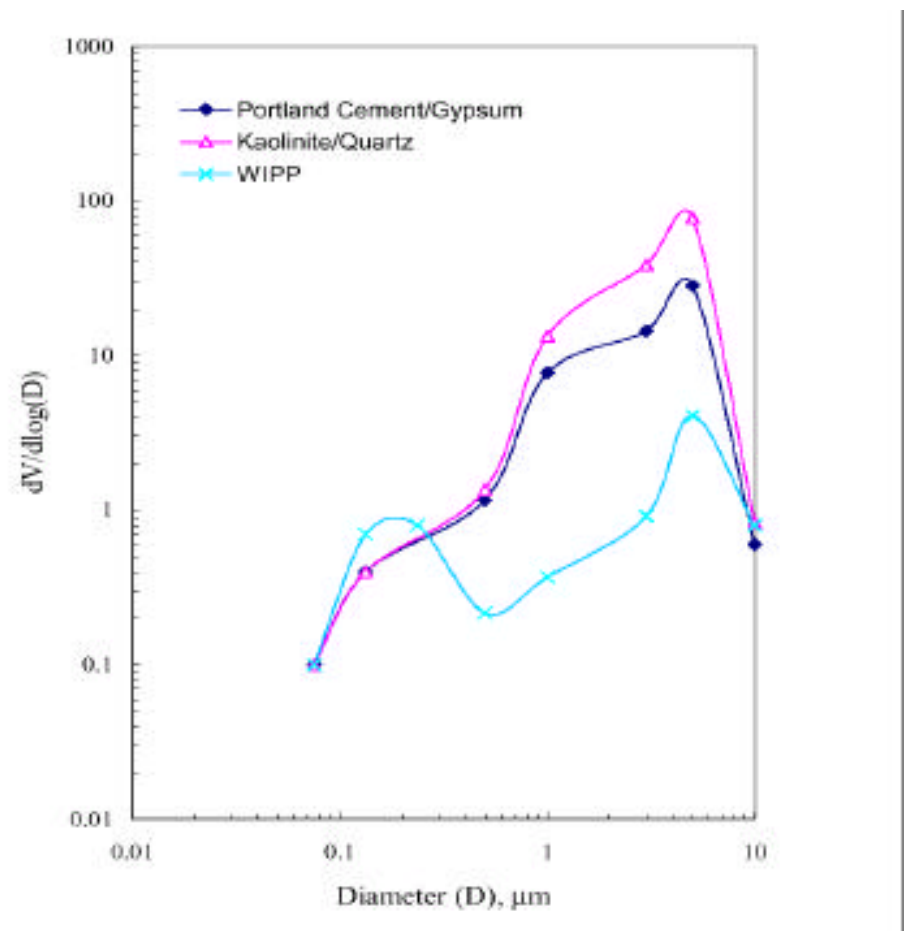

Figure 2. Volume-weighted size distributions for three different dusts. 
dust distributions for rural outdoor air. The $\mathrm{NaCl}$ salt dust was a special situation designed to simulate the atypical salt aerosol that can occur at WIPP, particularly at indoor locations due to the presence of the geological salt dome source. (The distribution for outdoors at WIPP in Figure 2 is NOT for salt but for the usual situation of background dust coming from off site.)

Figure 3 shows some representative data for the alpha particle energy resolution for the three types of dust and different size radioactive aerosol particles. This figure plots the full width at half maximum for the $7.69 \mathrm{MeV}$ alpha particle from decay of ${ }^{214} \mathrm{Po}$ for various thicknesses of the underlying nonradioactive dust reported in units of $\mathrm{mg} \mathrm{cm}^{-2}$. The radioactive aerosol particles, which were deposited as a final thin $\left(<0.1 \mathrm{mg} \mathrm{cm}^{-2}\right)$ layer, range in size from 0.002 to $10 \mu \mathrm{m}$. The filters were $1.0 \mu \mathrm{m}$ Millipore membrane filters. Although there is a trend of larger aerosol particles having poorer energy resolution (larger FWHM) due to energy loss in the particle itself, there is surprisingly no

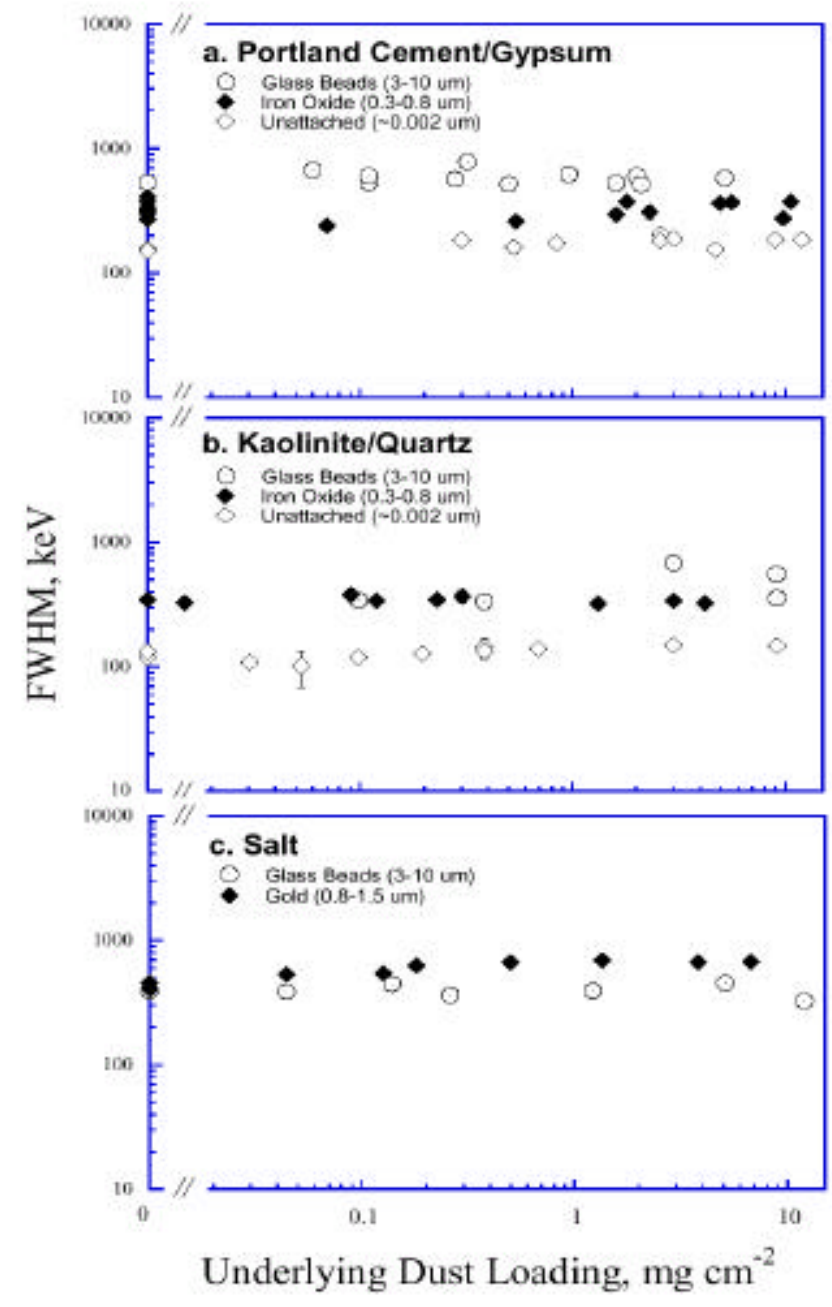

Figure 3. Full width at half maximum for a thin layer of radioactive aerosol particles on top of a thick layer of underlying nonradioactive dust. 
consistent trend of greater dust loading causing degraded resolution. One explanation is that the dust builds up on the filters in such a fashion as to simulate the surface of a fairly high quality filter. However, we did find that there was some variation in resolution as a function of filter type even when the dust layers were relatively thick $\left(>20 \mathrm{mg} \mathrm{cm}^{-2}\right)$. Further discussion of these points can be found in Huang et al. (2002) and Alcantara (2000).

\subsection{Test of a Prototype Virtual Impactor as the ECAM Preseparator}

In addition to studying dust loading on ECAM filters, we also investigated the feasibility of using a virtual impactor to improve ECAM sampling under advert environments. A virtual impactor is a device for selective collection of size-segregated aerosol particles based on impaction properties. Instead of deposition on impaction plates, large aerosol particles (i.e., with sufficient inertia) are carried by the (straight) minor flow entering a collection probe with narrow opening and are collected on a filter. Small particles, on the other hand, follow the main airflow turning to the side of the collection probe. Thus they are separated from the large particles and can be collected on another filter.

The nature of selective sampling of virtual impactors is considered to be useful to improve the robustness of ECAMs, especially in the environments with heavy loadings of aerosol particles. During the 2000 Cerro Grande/Los Alamos fire, CAM filters were clogged by smoke particles and thus were hindered from monitoring the radioactivity in the air. By using one or a parallel series of virtual impactors of proper design as the preseparator of ECAMs, fine particle aerosols, presumably dominated by nonradioactive smoke particles, can bypass the collection filter. Thus, the chance of filter clogging can be reduced, if not prevented, due to the reduction of the ECAM filter loading of fine particles. Radioactive aerosols such as plutonium and uranium aerosols were measured to be in the coarse size range; most of them should be retained for radioactivity measurement.

Based on the above considerations, a prototype virtual impactor was designed by LANL and was tested in our laboratory. Monodisperse silica microspheres with a series of size ranges were made radioactive by using our newly developed electrostatic deposition technique. The test results of this prototype are shown in Figure 4.

Since the test results agreed with previous studies, we further tested the impactor with various gaps to the collection probe, and a parallel series of four impactors. The gap has little effect on the cut-off diameter, but smaller gaps tend to have larger loss. A case of sudden release of radioactive aerosols onto a major flow filter close to clogging was simulated by using smoke from kerosene, cigarette, and a smoke generator, and radioactive gold aerosols. The results suggest little selective separation of the (small) smoke particles (so called "small particle contamination" in the literature). $94 \%$ of the radioactive gold particles went into the minor flow, but the internal radioactivity loss was $39 \%$. Therefore, the radioactivity with the virtual impactor(s) was only $\sim 60 \%$ of that without the virtual impactor(s). Our study indicates that the filter life could be extended by a factor of 10 by not sampling as much of the smoke particles and air. However, only about half of the radioactivity would be detected due to bypass and internal loss. On the 


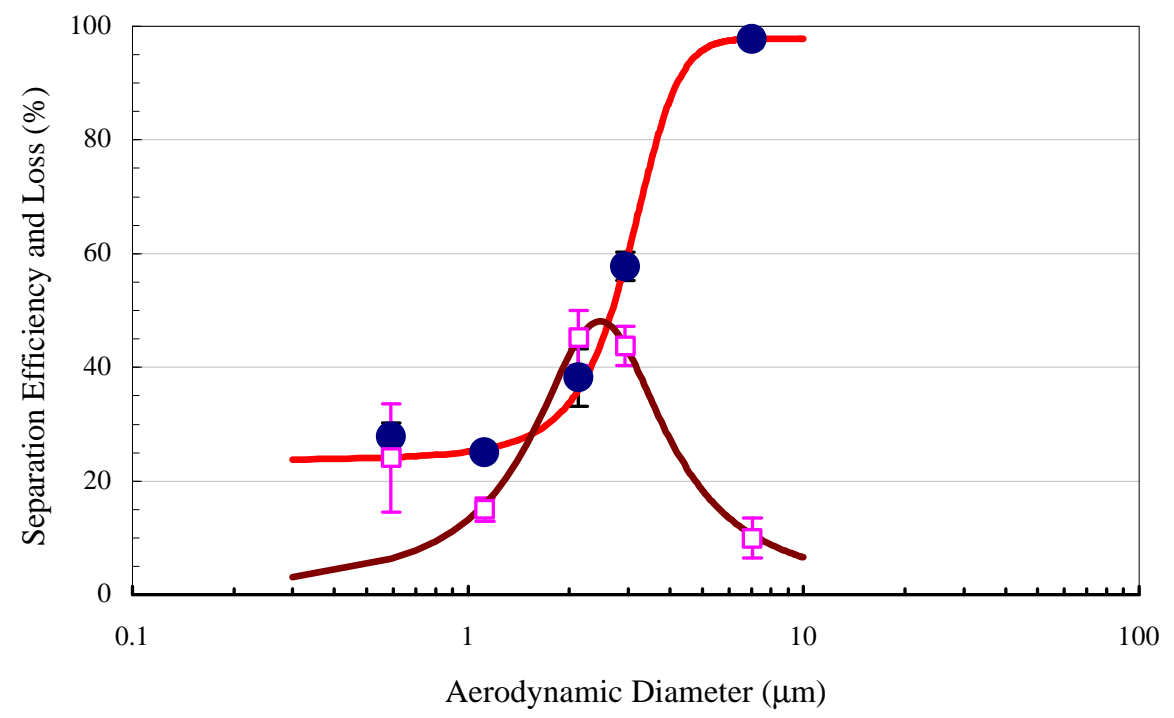

Figure 4. Separation efficiency (circles) and internal loss (open squares) of the

virtual impactor as a function of aerodynamic diameter of the particles.

other hand, if the central concern is sensitivity rather than filter clogging, a series of 10 virtual impactors in parallel, which clog at about the same rate as the ECAM without the impactors, would improve the sensitivity by a factor of 5 .

A manuscript about this test is in preparation for submission to Health Physics or Aerosol Science and Technology. 


\section{Relevance, Impact, and Technology Transfer}

At the time of the writing of this final report, it is a little early to assess the impact of our work on the practical needs of DOE laboratories and commercial companies involved in radioactive aerosol measurement. The reason is that our primary mechanism of transferring information is the two peer reviewed papers scheduled for publication in Health Physics. Although the reviewers' comments were positive (in fact, one reviewer of the second paper said it was the best Health Physics paper he had reviewed in over 20 years), we will not know the general impact on the health physics and environmental science community until the papers have appeared and there has been time for their assimilation and assessment.

The new technique (Huang et al., 2002a) for generation of micrometer-sized radioactive aerosol particles could be quickly put to use by other laboratories. It is a relatively straightforward, convenient way to produce radioactive aerosols of known size and radioactive content that does not require the extensive radiation safety procedures necessary for production and testing of some other types of radioactive aerosol particles. Savings in time, and the cost of radiation safety equipment and procedures, might be significant where this technique is applicable. Notably, besides producing test aerosol for instruments such as ECAMs and cascade impactors, this technique may prove valuable to other fields such as biomedical research. The development of this technique was not anticipated in our original proposal; it arose as a practical solution to meet our own problem of a simpler method of producing radioactive aerosols in a general purpose academic laboratory to test ECAMs. It is an example of a somewhat serendipitous discovery that argues for some continued flexibility to researchers receiving EMSP-type grants.

The second paper (Huang et al., 2002b) will provide new information to the scientific community about the behavior of ECAM filters in dusty environments. This work addresses an important problem identified by the health physics groups at LANL and other DOE labs of too frequent change of filters and false alarms with ECAMs, perhaps aggravated by dusty conditions. It certainly provides a backdrop of scientific information for future choice of operating conditions for ECAMs and development of new ECAMs. Its direct, short-term impact is less clear because we cannot forecast the subtle decisionmaking factors of people using ECAMs on a daily basis. Perhaps based on this paper certain users will make immediate changes in the type of filters they are using and the frequency with which filters are changed. However, perhaps in the face of their busy daily routines and/or knowledge of their local air-sampling conditions, the use of timetested procedures will seem the prudent course for some for the immediate future.

In the area of the investigation of the effect of dust on the alpha-particle energy resolution of ECAMs we feel we made more than satisfactory progress addressing the major questions. Further broad research would be valuable, particularly on better characterizing the patterns of dust on filters and their effect on clogging and energy resolution. However, we cannot point to a specific, practical need that could be quickly satisfied by continued research along the lines of the present research. In contrast, further investigation of the use of pulse ionization chambers for CAM detectors might benefit significantly by the right research team. We have identified what we think is the major issue: can a pulse ionization chamber be built with new preamp designs, sufficient energy 
resolution, and operated with air as the carrier gas using the slow (millisecond) pulse mode. If so, such ionization chambers might provide a real breakthrough for the sensitivity of ECAMs. This would be a high risk project, but we know commercial groups have designed related air ionization chambers for use in different contexts (such as the measurement of radon gas). Such a new project would require a lot of specialized expertise in electronics and signal processing, so the composition of the research team would have to be different from that of the present team.

One benefit of the present research was the training and experience it provided to our students and young scientists. This was an interdisciplinary, applied project for which it would be difficult to obtain training in standard academic courses. Unfortunately, as alluded to elsewhere in this report (section 15), some of this specialized training may go wasted. The hit-and-miss funding for specialized research of this type, and the fact that other fields are either more glamorous to many students (e.g., astrophysics) or more financially lucrative ( electrical engineering, medical research and development, etc.) make it difficult to keep scientists and students involved with this kind of work for the long term. If it were not for foreign-born students and researchers lured by the economic opportunities available at the USA higher education institutions, it would be virtually impossible to attract qualified engineers and scientists to projects like this. Students raised in the native American culture and high school system seem less and less attracted to the demanding work in the perceived "dull" hard sciences and are more interested in fields such as business, medicine, psychology, or, at best, computer science and electrical engineering (Silicon Valley variety). 


\section{Project Productivity}

Given the relative modest funding (\$309650) for a research project of this type, we feel the DOE obtained very good value for its money. For point of reference, this level of funding, considering usual overhead rates, would not even cover the salary of one Ph. D. level scientist at a national laboratory over a three year period, let alone all the other associated expenses (equipment, supplies, travel, etc.). This project was the primary object of attention of several Ph.D. scientists over a four year period. A graduate student worked on the project over three years. Two high-quality refereed papers and an M. S. thesis have resulted, in addition to a number of shorter talks and reports.

The project was about one year late in getting up to full speed due to the need to get a graduate student on line and replacement of one P. I. As a result, the project ran for a period of essentially four and a half years, instead of three. However, this increase in project period was done without any added cost to the DOE using no-cost extensions.

Some of the work on optical study and theory of formation of dust dendrites, which was anticipated in the original proposal, was not accomplished. Although an effort was made, we seemed to quickly reach a dead end with little productive advancement of knowledge in proportion to the effort put forward. In retrospect, we did not have sufficient funding for key equipment that was needed and we underestimated the expertise needed to design and interpret optical-imaging experiments. However, given the flexibility allowed in the project, the lack of productivity in dendrite studies was more than offset by our accomplishment in the development of a new technique to produce convenient radioactive aerosols. This serendipitous accomplishment had not been anticipated, or funded for, in the original proposal. Fortunately, ingenuity and inspiration, more than expensive equipment, were the key ingredients. We also think the flexible structure of the grant structure allowing room for a lot of local initiative was important to this type of advancement. Were we required to write a new or revised proposal anticipating development of a convenient new technique to generate micrometer-sized radioactive aerosols, this achievement would probably not have happened. 


\section{Personnel Associated with the Project}

Dr. Suilou Huang, Reseach Scientist, NMIMT, Principal Investigator, partial salary support

Dr. Stephen Schery, Emeritus Professor, NMIMT, Co-Principal Investigator

Dr. Piotr Wasiolek, Research Scientist, NMIMT, and Visiting Scientist, Los Alamos National Lab, Co-Principal Investigator

Mr. John Rodgers, Health Physicist, Los Alamos National Lab, Co-Principal Investigator

Dr. Qixu Mo, Visiting Scientist, NMIMT, partial salary support

Mr. Raul E. Alcantara, graduate student in physics, NMIMT, salary support of graduate student research assistantship, received M. S. degree from NMIMT, 2000.

Mr. Nathan Dale, undergraduate student in physics and electrical engineering, NMIMT, received partial salary support as student technician

Ms. Candice Scheffing, undergraduate student in chemical engineering, NMIMT, partial support as student technician

Ms. Sarah Lubshenco, undergraduate student in chemical engineering, NMIMT, partial support as student technician

Mr. David Hale, undergraduate student in mathematics and physics, NMIMT, partial support as student technician 


\section{Publications}

Alcantara, R. E., 2000, Studies of the Effect of Dust Loading on the Alpha-Particle Energy Spectrum for Radioactive Aerosol Particles Deposited on Filters, M. S. Thesis, New Mexico Institute of Mining and Technology, Socorro, NM

Huang, S, S. D. Schery, R. E. Alcantara, N. V. Dale, and J. C. Rodgers, 2002a, Micrometer-Sized Short-Lived Radioactive Aerosol Particles for Convenient Use in Laboratory Measurements, in press, Health Physics

Huang, S., S. D. Schery, R. E. Alcantara, J. C. Rodgers, and P. T. Wasiolek, 2002b, Influence of Dust Loading on the Alpha-Particle energy Resolution of Continuous Air Monitors for Thin Deposits of Radioactive Aerosols, accepted for publication, Health Physics 
10. Interactions

\subsection{Presentations}

Rodgers, J. C., P. T. Wasiolek, S. D. Schery, and R. E. Alcantara, 1998, High Resolution Real-Time Optical Studies of Radiological Air Sample Processes in an Environmental Continuous Air Monitor, 1998 SPIA Symposium on Industrial and Environmental Monitors and Biosensors, November 1-6, Boston, MA LA-UR-98-1684

Schery, S. D., S. Huang, R. E. Alcantara, P. T. Wasiolek, J. C. Rodgers, and R. Arimoto, 1999, The Effect of Dust Loading on the Detection of Radioactive Aerosol Particles with Continuous Air Monitors: Initial Lab Results, 1999 American Geophysical Union Fall Meeting, San Francisco, December, EOS Trans. AGU, Fall Meet. Suppl. 80, F1186

Huang, S., R. E. Alcantara, S. D. Schery, P. T. Wasiolek, and J. C. Rodgers, 2000, EMSP Annual Progress Report on Project 60163, EMSP National Workshop, Atlanta, Georgia, April 24-28.

Huang, S., Micrometer-Sized Short-Lived Radioactive Aerosol Particles for Safe and Convenient Use in Laboratory Measurements, 2000, Invited Oral Presentation, EMSP National Workshop, Atlanta, Georgia, April 24-28.

\subsection{Consultations}

Corning Incorporated

In exchange for filter samples, test results showing filter performance for potential use in alpha-particle detection ECAMs were provided to Ms. Tamara Allen, Product Manager Filters, Corning Inc., Acton, MA 01720.

Alexander Vaccum Research

In exchange for samples of metalized films, test results for their potential use as windows for pulse ionization chambers were provided to Mr. Ronal Aleman, Alexander Vacuum Research, Greenfield, MA 01301.

STARENVIRONTECH ${ }^{\mathrm{TM}}$, Inc.

In negotiation for price, particle size information for the smoke from their smoke generators were provided to Mr. Ken Pieroni, STARENVIRONTECH ${ }^{\mathrm{TM}}$, Inc., Costa Mesa, CA 92626.

Bangs Laboratories, Inc., Fishers, IN 46038-2886

Wrong size categorization on one of their silica microspheres was identified and was pointed out to one of their technicians. 
11. Transitions

See section 10.2.

\section{Patents}

none

13. Future Work

see section 6 . 


\section{Literature Cited}

Alcantara, R. E., 2000, Studies of the Effect of Dust Loading on the Alpha-Particle Energy Spectrum for Radioactive Aerosol Particles Deposited on Filters, M. S. Thesis, New Mexico Institute of Mining and Technology, Socorro, NM

Hoover, M. D. and G. J. Newton, 1993, Radioactive Aerosols, IN Willeke and Baron, Aerosol Measurement: Principles, Techniques, and Applications, Van Nostrand Reinhold, New York, page 792.

Huang, S, S. D. Schery, R. E. Alcantara, N. V. Dale, and J. C. Rodgers, MicrometerSized Short-Lived Radioactive Aerosol Particles for Convenient Use in Laboratory Measurements, accepted for publication, Health Physics

Huang, S., S. D. Schery, R. E. Alcantara, J. C. Rodgers, and P. T. Wasiolek, 2001, Influence of Dust Loading on the Alpha-Particle energy Resolution of Continuous Air Monitors for Thin Deposits of Radioactive Aerosols, accepted for publication, Health Physics

Johansson, L., B. Roos, and C. Samuelsson, 1992, Alpha-Particle Spectrometry of LargeArea Samples using an Open-Flow Pulse Ionization Chamber, Appl. Radiat. Isot. 43,119 . 


\section{Feedback}

The following comments are those of the senior member (Dr. S. D. Schery) associated with the project. Dr. Schery drew no salary support from grant and has now retired to Emeritus Professor of Physics at NMIMT.

I think key virtues of this EMSP grant in the way in which it was awarded to us were

1) an upfront award for the entire grant period, and

2) some flexibility in locally administering the personnel and funds plus some restraint in requiring excessive paperwork, reports, milestones, etc.

At NMIMT, as at many U. S. institutions of higher learning, grant and contract funding is a hit-and-miss process with little backup financial support from the school administration. It often takes over a year to recruit graduate students and scientists. And you cannot start recruitment until you have the money. With appointments totally dependent on grant and contract money, it is difficult to attract high-quality people if you can only assure salary support one year at a time. The availability of a three-year budget (dependent of course on satisfactory performance) was a key ingredient in attracting people whose salary depended on the grant.

For work with a strong research component, point 2 above is important because it is difficult to program accomplishments with research. Furthermore, in an academic environment such as NMIMT, faculty have diverse obligations and it takes time to recruit and train students and new scientists. Often in the academic environment a project will start out slowly as students and scientists are broken in. But then it will finish in a very robust, productive state because the students and young researchers have become fully trained and are worth much more than their entry-level salaries programmed into the budget.

On the negative side of the grant procedure process I would make the following observations (also see Section 6 above). The graduate student and Ph. D. scientists whose salaries were paid for from this grant (all foreign born) have left this area of research for other fields. Some of them were still interested in pursuing this type of research, but found that they must engage in proposal writing and other self-promotional and administrative activities at an aggressive, adversarial level that is beyond their training and sensibilities. At best, resulting funding prospects will be uncertain after a few years. Why put yourself through this unpleasant and uncertain process if somebody will offer you a more secure job in a more glamorous field at a higher salary? I myself have opted out of the grant and contract process a little earlier than I might otherwise. It is a demanding, less-than-pleasant process, and I've noted that many colleagues who do not go through it often seem to do quite well with their careers.

I have no quick solutions to the above problem. I just note that the fundraising process places a premium on salesmanship, self-promotion, and insider information. Scientific talent, scientific potential, and scientific merit need to be more aggressively 
sought out by grant administrators rather than passively relying so strongly on the sales pitch given by the proposal writers. We are loosing many young, technically talented scientists who are otherwise quite capable and willing to do the research we need but do not have a pit bull instinct for self-promotion and scientific administration. I often think much of our research funding ends up going to articulate, well-connected senior scientists who no longer have the time, nor up-do-date skills, to effectively spend the money they are so successful at collecting. However, since these people are so effective at putting the correct "spin" on their activities, no one is ever the wiser about a dearth of genuine underlying scientific productivity. 
A. Abstract of M. S. Thesis of R. E. Alcantara, 2000, Studies of the Effect of Dust Loading on the Alpha-Particle Energy Spectrum for Radioactive Aerosol Particles, New Mexico Institute of Mining and Technology, Socorro, NM.

B. Abstract of S. Huang, S. D. Schery, R. E. Alcantara, N. V. Dale, and J. C. Rodgers, Micrometer-Sized Short-Lived Radioactive Aerosol Particles for Convenient Use in Laboratory Measurements, accepted for publication, Health Physics

C. Abstract of S. Huang, S. D. Schery, R. E. Alcantara, J. C. Rodgers, and P. T. Wasiolek, Influence of Dust Loading on the Alpha-Particle Energy Resolution of Continuous Air Monitors for Thin Deposits of Radioactive Aerosols, accepted for publication, Health Physics 


\section{ABSTRACT (R. Alcantara, M.S. Thesis)}

\section{Studies of the Effect of Dust Loading on the Alpha-Particle Energy Spectrum for Radioactive Aerosol Particles Deposited on Filters}

Continuous air monitors (CAMs) are used to monitor alpha-emitting aerosols at places that handle/process transuranic elements. The CAM utilizes an alpha-particle detector located over a high flow filter to detect the presence of the radioactive aerosols. An environmental continuous air monitor (ECAM) is similar to the CAM unit, but it is optimized to work at outdoor settings. ECAM units can encounter large amounts of dust which can have a negative impact on their ability to monitor alpha-particle emitting aerosols.

This study tries to quantify and understand the effects that a dust layer collected on a membrane filter can have on the alpha-particle energy of radioactive aerosols deposited over or within the dust. Two types of experiments were carried out to quantify and understand the energy spectrum degradation: a thin layer of alpha-particle emitting aerosols deposited over a dusty filter, and a thick layer of alpha-emitting aerosol deposited on a filter.

A computer model was developed to bring a better understanding of the experiments dealing with the alpha-emitting aerosols on the dusty filter. This model evaluates the self-absorption of alpha-particle in the radioactive aerosol itself. The simulation evaluates the self-absorption of spherical aerosols with volume or surface distributed alpha radioactivity.

Laboratory measurements made use of a new solution to the problem of generating radioactive aerosols. This technique involves electrostatic deposition of radionuclides on powders. The technique proved to be an important part of this work since production of radioactive aerosols often requires sophisticated safety equipment that is not available at our laboratory. The technique also allowed flexibility in choosing chemical composition and physical characteristics of the alpha-radioactive aerosol.

The following are the major findings from this thesis research:

${ }^{*}$ For the dusts and filters studied, an underlying layer of non-radioactive dust has little effect on alpha-particle energy resolution. This finding suggests that ECAMs might be able to detect sudden releases of alpha-radioactive aerosols even if a thick dust cake has formed on the surface of its filter.

* In contrast, it was found that thick layers of alpha-radioactive aerosols cause an increasing deterioration of energy resolution with increasing layer thickness. This might indicate that an ECAM will not be able to detect chronic releases of alpha-radioactive aerosols.

*Measurements showed that self-absorption of alpha-particle emissions in the aerosol particles themselves produces a noticeable effect on alpha-particle energy resolution.

*Finally, the results from the computer simulation showed that the situations of volume and surface alpha radioactivity on spherical particles can have a significant effect on the shape of the energy peak. For larger aerosol radii the alpha-particle energy spectra of surface-radioactive aerosols showed less degradation than that of the volume-radioactive aerosols. 


\title{
MICROMETER-SIZED SHORT-LIVED RADIOACTIVE AEROSOL PARTICLES FOR CONVENIENT USE IN LABORATORY MEASUREMENTS
}

\author{
S. Huang ${ }^{1}$, S. D. Schery ${ }^{1}$, R. E. Alcantara ${ }^{1}$, N. V. Dale ${ }^{1}$, and J. C. Rodgers ${ }^{2}$ \\ ${ }^{1}$ Atmospheric Radioactivity Group, Geophysical Research Center \\ New Mexico Institute of Mining and Technology \\ Socorro, NM 87801, suilou@nmt.edu, phone: 505-835-5993, FAX: 505-835-5707 \\ ${ }^{2}$ Los Alamos National Laboratory \\ Health Physics Measurements, ESH-4 \\ Mail Stop G761, Los Alamos, NM 87545 \\ Health Physics (In Press) \\ 1 August 2001
}

\begin{abstract}
For calibration and testing of radioactive aerosol measuring equipment such as continuous air monitors and cascade impactors, and other research applications, it is helpful to have a convenient and relatively safe means of producing radioactive aerosol particles of controlled size and activity. We describe a technique for producing such particles in the micrometer-diameter size range using electrostatic deposition of radon decay products onto otherwise nonradioactive powders of different sizes. An electric field focuses radon decay products (primarily ${ }^{218} \mathrm{Po}$ ) onto the surface of a powdered substrate that is then suspended by a technique such as pneumatic dry dispersion. Only a modestactivity commercial ${ }^{222} \mathrm{Rn}$ source (e.g., containing as little as $10^{5} \mathrm{~Bq}$ of ${ }^{226} \mathrm{Ra}$ ) is required, and issues of radioactive cleanup and contamination are minimized due to the short halflives (26.8 min or less) of the decay products. We report representative results using powders of glass beads, iron oxide, and iron and gold metals in the size range of 0.3 to 30 ì m. Yields for the deposited radioactivity per unit concentration of ${ }^{222} \mathrm{Rn}$ gas were of the order of $5 \times 10^{-7} \mathrm{~Bq}\left({ }^{214} \mathrm{Bi}\right)$ per milligram substrate per $\mathrm{Bq} \mathrm{m}^{-3}$ of ${ }^{222} \mathrm{Rn}$ for an electrostatic collection time of $30 \mathrm{~min}$.
\end{abstract}




\title{
INFLUENCE OF DUST LOADING ON THE ALPHA-PARTICLE ENERGY RESOLUTION OF CONTINUOUS AIR MONITORS FOR THIN DEPOSITS OF RADIOACTIVE AEROSOLS
}

Suilou Huang*, Stephen D. Schery*, Raul E. Alcantara*, John C. Rodgers ${ }^{\dagger}$, and Piotr T. Wasiolek ${ }^{\dagger}$ *Atmospheric Radioactivity Group, Geophysical Research Center, New Mexico Institute of Mining and Technology, Socorro, NM 87801, suilou@nmt.edu, phone: 505-835-5993, FAX: 505-835-5707

${ }^{\dagger}$ Los Alamos National Laboratory, Health Physics Measurements, ESH-4, Mail Stop G761, Los Alamos, NM 87545

\section{Accepted for publication in Health Physics}

September 12001

\begin{abstract}
The response of alpha-particle continuous air monitors (CAMs) in high dust environments is of interest because of possible false alarms caused by degradation of peak shape in the energy spectrum. For the case of a thin-layer deposit of radioactive aerosol particles on top of a thick layer of background dust, a series of laboratory experiments were conducted to investigate factors affecting the alpha-particle energy resolution. Aerosol particles of various sizes were tagged with radon decay products to serve as surrogates for radioactive aerosols of interest such as plutonium or uranium. While the size of radioactive aerosols, filter type, and dust type affected the energy resolution, the thickness of the underlying dust layer did not show significant effect for the materials studied and a loading range of $0.01-10 \mathrm{mg} \mathrm{cm}^{-2}$. Our results indicate that it is possible for CAMs to detect the release of radioactive aerosols with little deterioration in energy resolution under conditions of significant dust loading provided that the deposited layer of radioactive aerosols remains thin $\left(\leq 0.1 \mathrm{mg} \mathrm{cm}^{-2}\right)$.
\end{abstract}

